\title{
Development of Photosensitive Poly(hydroxyimide) with High Refractive Index
}

\author{
Tomohito Ogura, Tomoya Higashihara, and Mitsuru Ueda* \\ Department of Organic and Polymeric Materials, Graduate School of Science and Engineering, \\ Tokyo Institute of Technology, 2-12-1 H-120, O-okayama, Meguro-ku, Tokyo 152-8552, Japan \\ ueda.m.ad@m.titech.ac.jp
}

\begin{abstract}
A positive-type chemically amplified photosensitive poly(hydroxyimide) (PSPHI) based on the partially imidized poly(hydroxyimide) (PHI) prepared from $4,4^{\prime}-[p$ thiobis(phenylenesulfanyl)]diphthalic anhydride and bis(3-amino-4-hydroxyphenyl)sulfone, 9,9-bis[4-(tert-butoxycarbonyl-methyloxy)phenyl]fluorene (TBMPF) as a dissolution inhibitor, and (5-propylsulfonyloxyimino-5H-thiophen-2-ylidene)-(2methylphenyl)acetonitrile (PTMA) as a photoacid generator has been developed. This PSPHI consisting of the partially imidized PHI (80wt\%), TBMPF (16 wt \%), and PTMA (4 $\mathrm{wt} \%$ ) showed high transparency in the $450 \mathrm{~nm}$ wavelength and high refractive index of 1.698 and low birefringence of 0.0025 . The PSPHI exhibited high sensitivity of 25 $\mathrm{mJ} / \mathrm{cm}^{2}$ and high contrast of 8.4 when it was exposed to a $436 \mathrm{~nm}$ line ( $g$-line), postexposure baked at $130^{\circ} \mathrm{C}$ for $2 \mathrm{~min}$, and developed with an aqueous alkaline developer, $2.38 \mathrm{wt} \%$ tetramethylammonium hydroxide solution $/ 10 \mathrm{wt} \%$ iso-propanol at $25{ }^{\circ} \mathrm{C}$. A clear positive pattern of $4 \mu \mathrm{m}$ line and space was obtained on a film exposed to 50 $\mathrm{mJ} / \mathrm{cm}^{2}$ of $g$-line by a contact printing method.

Keywords: poly(hydroxyimide), photosensitive polymer, high reflective index, chemically amplified system
\end{abstract}

\section{Introduction}

Sulfur-containing polyimides (PIs) have attracted attention in the optical material fields because these PIs show high refractive index (high- $n$ ), low birefringence $(\Delta n)$, good thermal stability, and high mechanical property. Therefore, they are the most suitable polymers for inner lens materials of high-performance complementary metal-oxide semiconductor (CMOS) image sensors, which required those properties. Several highly refractive and sulfurcontaining new PIs derived from various aromatic dianhydrides and aromatic diamines have been reported. [1]

To fabricate inner lens in CMOS image sensors, the high- $n$ PIs are also required to have a good pattern formability by the conventional photolithography technique as well as low birefringence, good transparency in the visible light region, and high thermal stability. Recently, we have developed high- $n$ photosensitive PIs
(PSPIs) and fine negative-tone patterns were obtained.[2] Moreover, the positive-type high- $n$ PSPIs are required to obtain finer and better shape of patterns than the negative-type ones. However, it is generally difficult to formulate positive-type PSPIs because the dissolution rate of poly(amic acid)s (PAAs) in a $2.38 \mathrm{wt} \%$ tetramethylammonium hydroxide solution (TMAHaq.) is too high to obtain proper dissolution contrast between exposed and unexposed areas. On the other hand, poly(hydoroxyimides) (PHIs) have appropriate dissolution behavior to alkaline developer because of reasonable $\mathrm{p} K_{\mathrm{a}}$ of phenol unit. Therefore, many positive-type photosensitive PHIs (PSPHIs) were reported. [3]

In this work, we prepared a new high- $n$ PHI by the polymerization of $4,4^{\prime}-[p$-thiobis(phenylenesulfanyl)]diphthalic anhydride (3SDEA) with bis(3-amino-4-hydroxyphenyl)sulfone (BAHS), and report a positive-type PSPHI based on the partially imidized PHI, 9,9-bis[4-(tert- 
butoxycarbonyl-methyloxy)phenyl]fluorene (TBMPF) as a dissolution inhibitor, [4] and (5propylsulfonyloxyimino- $5 H$-thiophen-2ylidene)-(2-methylphenyl)acetonitrile (PTMA) as a photoacid generator.

\section{Experimental}

\subsection{Materials}

$N, N$-Dimethylacetamide (DMAc) was purified by vacuum distillation. PTMA kindly donated by Ciba Specialty Chemicals Co., Ltd., was used without further purification. TBMPF and 3SDEA were prepared according to the reported procedure. $[4,5]$ BAHS is commercially available monomer and used after recrystallization from ethanol and water. TMAHaq purchased from AZ Electronic Materials (JAPAN) K. K. Other chemicals were used as received unless otherwise noted. The chemical structures of monomers, TBMPF, and PTMA are shown in Scheme 1.
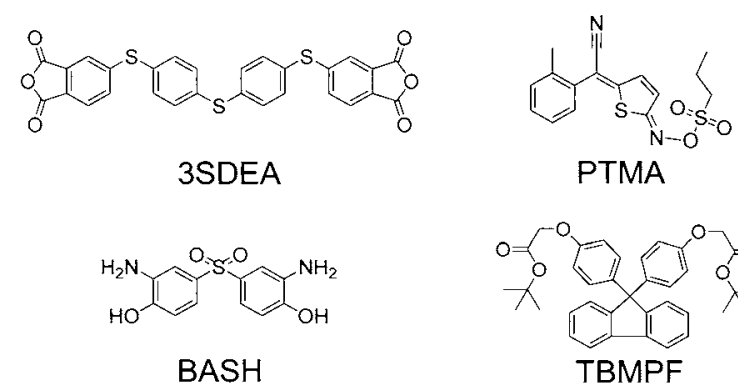

Scheme 1. Chemical structures of monomers, PAG, and dissolution inhibitor.

\subsection{Synthesis of partially imidized PHI (PIPHI)}

3SDEA (1.38 g, $2.54 \mathrm{mmol})$ was added to a solution of BAHS $(0.840 \mathrm{~g}, 3.00 \mathrm{mmol})$ in DMAc $(13.0 \mathrm{~mL})$, and then the mixture was stirred at room temperature for $24 \mathrm{~h}$ to give a viscous yellow solution. $o$-Xylene $(20 \mathrm{ml})$ as a azeotropic solvent was added to the polymer solution. The resulting mixture was heated at $165^{\circ} \mathrm{C}$ for $6 \mathrm{~h}$ for thermal cyclization. After the reaction was complete, the polymer was precipitated into water and dried overnight at $100{ }^{\circ} \mathrm{C}$ under reduced pressure. The yellow powder of PIPHI was obtained $(1.88 \mathrm{~g}, 93 \%)$. The inherent viscosity of this PIPHI was 0.14 $\mathrm{dL} / \mathrm{g}$ at a concentration of $0.50 \mathrm{dL} / \mathrm{g}$ in DMAc at $30{ }^{\circ} \mathrm{C}$.

\subsection{Film Preparation of PHI}

The partially imidized PHI was dissolved in cyclohexanone and the polymer solution was spin-casted on a silicon wafer to form a polymer film. The film was heated on a hot plate at 200 ${ }^{\circ} \mathrm{C}$ for $15 \mathrm{~min}$. The complete imidization of polymer film was confirmed by thermogravimetry (TG) analysis and ${ }^{1} \mathrm{H}$ nuclear magnetic resonance (NMR). IR (film on $\mathrm{Si}$ wafer, $\left.\varpi, \mathrm{cm}^{-1}\right): 3374(\mathrm{O}-\mathrm{H}), 1778(\mathrm{C}=\mathrm{O}), 1724$ $(\mathrm{C}=\mathrm{O}), 1600(\mathrm{Ar}), 1504(\mathrm{Ar}), 1376(\mathrm{C}-\mathrm{N}), 1303$ $\left(\mathrm{SO}_{2}\right), 1149\left(\mathrm{SO}_{2}\right) .{ }^{1} \mathrm{H}$ NMR $\left(\mathrm{CDCl}_{3}, \delta, \mathrm{ppm}\right)$ : 7.80-7.92 (m, 3H), 7.64-7.71 (m, 1H), $7.62(\mathrm{~s}$, $1 \mathrm{H}), 7.57(\mathrm{~d}, 2 \mathrm{H}), 7.47(\mathrm{~d}, 2 \mathrm{H}), 7.15(\mathrm{~d}, 2 \mathrm{H})$.

\subsection{Dissolution Rate}

PIPHI, TBMPF and PTMA were dissolved in cyclohexanone to prepare a photosensitive polymer. The polymer film was spin-casted from the solution ( $15 \mathrm{wt} \%$ concentration) on a silicon wafer and prebaked at $100{ }^{\circ} \mathrm{C}$ for $2 \mathrm{~min}$, then exposed to a filtered ultra-high-pressure mercury lamp at $436 \mathrm{~nm}$ ( $g$-line), followed by PEB at set conditions. The exposed film was developed with $2.38 \mathrm{wt} \%$ TMAHaq. $/ 10 \mathrm{wt} \% i \mathrm{PrOH}$ at 25 ${ }^{\circ} \mathrm{C}$ and measured change of film thickness before and after the development to determine the dissolution rate $(\AA / \mathrm{sec})$.

\subsection{Photosensitivity}

The polymer film with $1.7 \mu \mathrm{m}$ thickness on a silicon wafer was exposed to light at a wavelength of $g$-line, developed with $2.38 \mathrm{wt} \%$ TMAHaq. $/ 10 \mathrm{wt} \% i \mathrm{PrOH}$ at $25^{\circ} \mathrm{C}$ for $5 \mathrm{sec}$, and rinsed in water. A characteristic sensitivity curve was obtained by plotting normalized film thickness to the exposure dose $\left(\mathrm{mJ} / \mathrm{cm}^{2}\right)$. The image exposure was carried out in a contactprinting mode.

\subsection{Measurements}

The FT-IR spectra were obtained on a Horiba FT-210 spectrophotometer. The ${ }^{1} \mathrm{H}$ and ${ }^{13} \mathrm{C}$ NMR spectra were recorded on a BRUKER GPX300 (300 MHz) spectrometer. Thermal analysis was performed on a Seiko EXSTAR 6000 TG/DTA 6300 thermal analyzer at a heating rate of $10^{\circ} \mathrm{C} / \mathrm{min}$ for TG and a Seiko EXSTAR 6000 DSC 6200 connected to a cooling system at a heating rate of $10^{\circ} \mathrm{C} / \mathrm{min}$ for differential scanning calorimetry (DSC). Ultraviolet - visible (UV - vis) spectra were measured by a Jasco V-560 spectrophotometer. Film thickness on silicon wafer was measured by a Veeco Instrument Dektak ${ }^{3}$ surface profiler. The scanning electron microscope (SEM) photos 
were taken with a Technex Lab Tiny SEM 1540 scanning electron microscope with $15 \mathrm{kV}$ accelerating voltage for imaging. Refractive indices of PHI and the PSPHI films formed on quartz substrates were measured at a wavelength of $1320 \mathrm{~nm}$ at room temperature with a Metricon model PC-2000 prism coupler. The in-plane $\left(n_{\mathrm{TE}}\right)$ and out-of-plane $\left(n_{\mathrm{TM}}\right)$ refractive indices of PI films were measured with a prism coupler equipped with a half-waveplate in the light-path and a He-Ne laser light source (wavelength: 633 $\mathrm{mm}) . n_{\mathrm{TE}} / n_{\mathrm{TM}}$ and birefringence $(\Delta n)$ were calculated as a difference between $n_{\mathrm{TE}}$ and $n_{\mathrm{TM}}$. The average refractive index was calculated according to equation: $n_{\mathrm{AV}}=\left[\left(2 n_{\mathrm{TE}}^{2}+n_{\mathrm{TM}}{ }^{2}\right) / 3\right]^{1 / 2}$. The dielectric constant at $1 \mathrm{MHz}$ frequency was calculated from the following empirical equation, $\varepsilon=1.1 n^{2}{ }_{\mathrm{AV}}$, where $n_{\mathrm{AV}}$ is an average refractive index.

\section{Results and Discussion}

3.1. Preparation and Properties of PHI film

PHIs are easily obtained from poly(hydroxyl amic acids) which is prepared from aromatic dianhydrides and bis(o-aminophenols) by an one-pod method. [6] However, the PHI obtained from 3SDEA and BAHS showed high hydrophobicity and low solubility in $2.38 \mathrm{wt} \%$ TMAHaq. due to hydrophobicity of 3SDEA. Therefore, a PPHI which is soluble in $2.38 \mathrm{wt} \%$ TMAHaq. was prepared by controlling the azeotropic temperature. Imidization percentage of the PIPHI was $77 \%$, which was estimated by ${ }^{1} \mathrm{H}$ NMR.

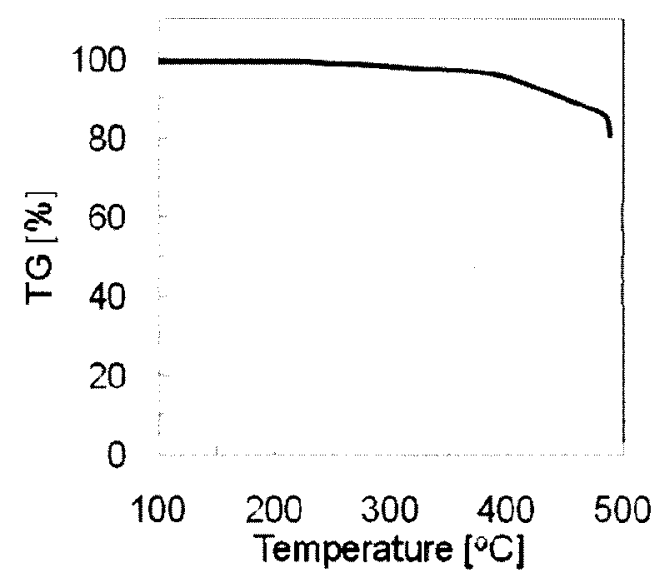

Figure 1. TGA curves of PHI films (under a nitrogen atmosphere, $10^{\circ} \mathrm{C} / \mathrm{min}$ ).

Thermal stability and transparency of the PHI film after curing at $200{ }^{\circ} \mathrm{C}$ for $30 \mathrm{~min}$ were measured because these properties are the key parameters of high- $n$ optical polymers when considering the high-temperature circumstance during fabrication and the long-term heatreleasing environment resulting from the miniaturization of optoelectronic devices. [7] $T_{\mathrm{d} 5 \%}$ and $T_{\mathrm{g}}$ values of the PHI film are 404 and $247{ }^{\circ} \mathrm{C}$, respectively (Figure 1). The PHI film shows high thermal stability suitable for inner lens material.

The transparency at UV - vis region is especially important for application of the PHI as a matrix polymer for PSPHI. The UV-vis spectra of the PHI film with a thickness of 2.1 $\mu \mathrm{m}$ is shown in Figure 2. The transmittances of the PHI film measured at 436 ( $g$-line) and 450 $\mathrm{nm}$ wavelengths are 78 and $87 \%$, respectively. General sulfur-containing PIs have strong absorptions at $g$-line and $450 \mathrm{~nm}$ wavelengths due to inter or intramolecular charge transfer interaction between electron-donating diamine moiety and the electron-accepting dianhydride moiety. In contrast, the PHI showed high transparency at these wavelengths because high ionization potential of BAHS increases the band-gap energy for charge transfer interaction. [8] These results indicated that the PHI has enough thermal stability and transparency at $g$ line as the matrix polymer of PSPHI.

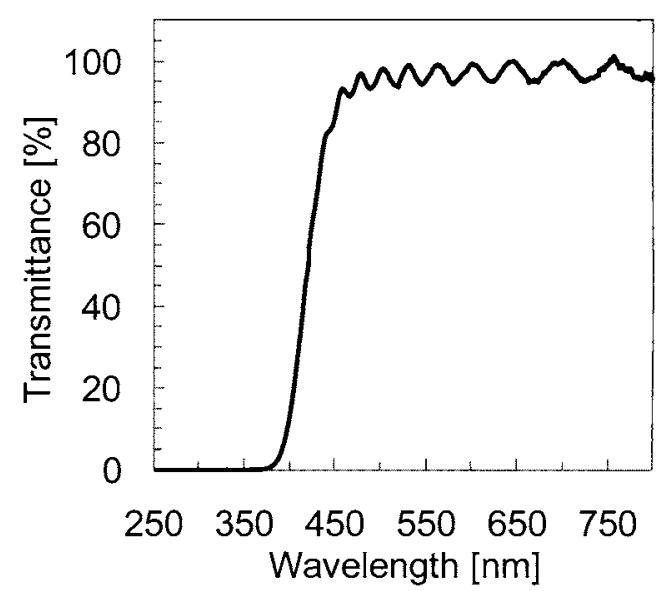

Figure 2. Experimental UV/vis transmission spectra of the PHI film.

\subsection{Lithographic Evaluation}

The patterning process of this PSPHI is shown in Scheme 2. The formulation of PSPHI is simple, involving addition of TBMPF and PTMA to a PIPHI solution. Upon irradiation of $g$-line, propanesulfonic acid generated from PTMA, and subsequent post-exposure baking (PEB) deprotected the tert-butyl ester of TBMPF with the acid catalyst. This catalytic 
decomposition reaction realizes a chemically amplified system. The corresponding carboxylic acids from TBMPF and PIPHI at exposed areas promote dissolution of PIPHI in an aqueous alkaline developer, $2.38 \mathrm{wt} \%$ TMAHaq. On the other hand, the film of the unexposed areas is insoluble in TMAHaq. due to high hydrophobicity of TBMPF. Therefore, the positive patterns of PSPHI are obtained after the development.

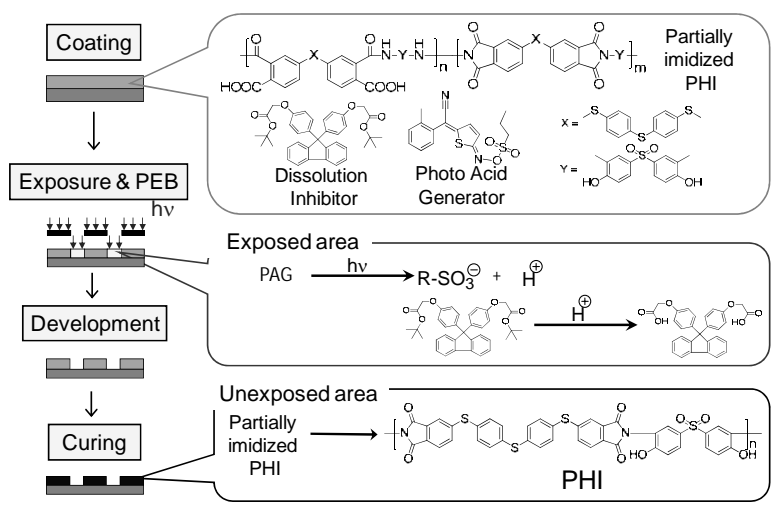

Scheme 2. Patterning process of PSPHI.

The effects of TBMPF loading, PEB temperature, and PEB time on the dissolution rate of PIPHI in $2.38 \mathrm{wt} \%$ TMAHaq. were investigated to obtain contrasting pattern profiles from exposed and unexposed areas. The photosensitive films were formed by spincasting from PSPHI cyclohexanone solution containing PIPHI, TBMPF, PTMA on a silicon wafer. The film was dried at $100{ }^{\circ} \mathrm{C}$ for $2 \mathrm{~min}$ in air and irradiated with UV light with $g$-line using a filtered super-high-pressure mercury lamp. Subsequently, it was baked at a set temperature, and developed with 2.38 wt\% TMAHaq. / $10 \mathrm{wt} \%$ iso-propanol $(\mathrm{iPrOH})$ at $25{ }^{\circ} \mathrm{C}$. The dissolution rates at the exposed and unexposed areas were estimated by the change in film thickness before and after the development. The addition of $10 \mathrm{wt} \% \mathrm{iPrOH}$ to 2.38 wt\% TMAHaq improved compatibility between the partially imidized PHI and the developer.

At first, the effect of TBMPF loading on the dissolution rate of the film was investigated (Figure 3). Although the PSPHI film at the unexposed area, consisting of $10 \mathrm{wt} \%$ TBMPF to the partially imidized PHI dissolves in the developer, the dissolution rate becomes nearly zero under $20 \mathrm{wt} \%$ TBMPF loading to the PIPHI [corresponding to PIPHI (80 wt\%), TBMPF (16 wt\%), and PTMA (4 wt\%)].
A PEB process is crucial for the chemically amplified resist system because the diffusion of the acid generated from PTMA depends on the PEB condition. The dissolution rates between the exposed and unexposed areas were measured at in the range from 100 to $150{ }^{\circ} \mathrm{C}$ (Figure 4). The dissolution rate of the exposed increases with increasing PEB temperature, and becomes constant above $130{ }^{\circ} \mathrm{C}$. The dissolution contrast DC) between the exposed and unexposed areas in $2.38 \mathrm{wt} \%$ TMAHaq / $10 \mathrm{wt} \% \mathrm{iPrOH}$ reaches 2500 times over the PEB temperature of $130^{\circ} \mathrm{C}$. This dissolution behavior was approximately the same as a previous work. [4]

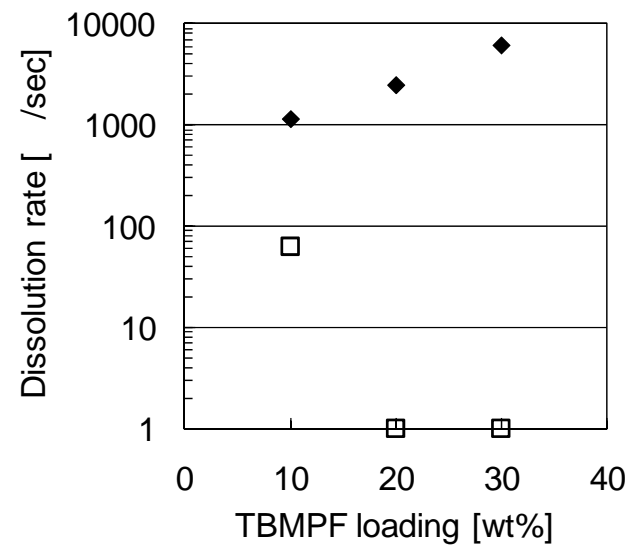

Figure 3. Effect of TBMPF loading on the dissolution rate for PIPHI/PTMA (95/5 wt/wt) resist system in exposed ( $\downarrow$ ) and unexposed ( $\square$ ) areas. The prebake, $g$ line exposure, and PEB conditions were at $100{ }^{\circ} \mathrm{C}$ for $2 \mathrm{~min}$, at $200 \mathrm{~mJ} / \mathrm{cm}^{2}$, and at $130{ }^{\circ} \mathrm{C}$ for $2 \mathrm{~min}$, respectively.

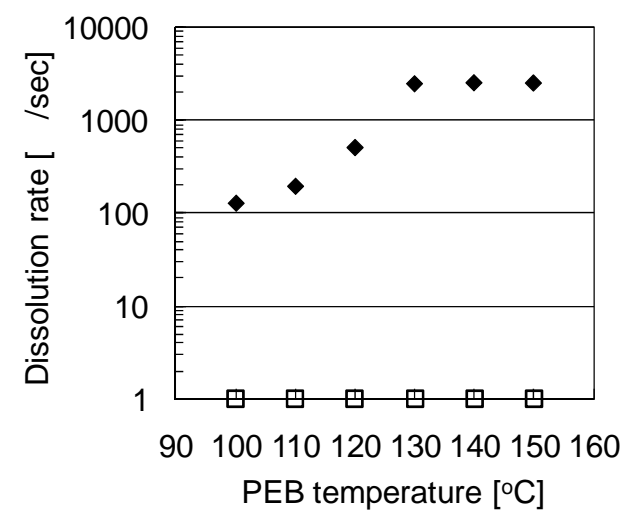

Figure 4. Effect of PEB temperature on dissolution rate for PIPHI/TBMPF/PTMA (80/16/4 wt/wt/wt) resist system in exposed $(\diamond)$ and unexposed $(\square)$ areas. The prebake, $g$-line exposure, and PEB time were fixed at $100{ }^{\circ} \mathrm{C}$ for $2 \mathrm{~min}$, at $200 \mathrm{~mJ} / \mathrm{cm}^{2}$ and for 2 min, respectively.

In a similar way, the effect of PEB time on the dissolution rate of the film was studied at $130{ }^{\circ} \mathrm{C}$ 
PEB temperature (Figure 5). The film at the exposed area dissolves quickly in the developer even for $20 \mathrm{~s}$ PEB time and the dissolution rate of the exposed area is saturated at $80 \mathrm{~s}$ of PEB time.

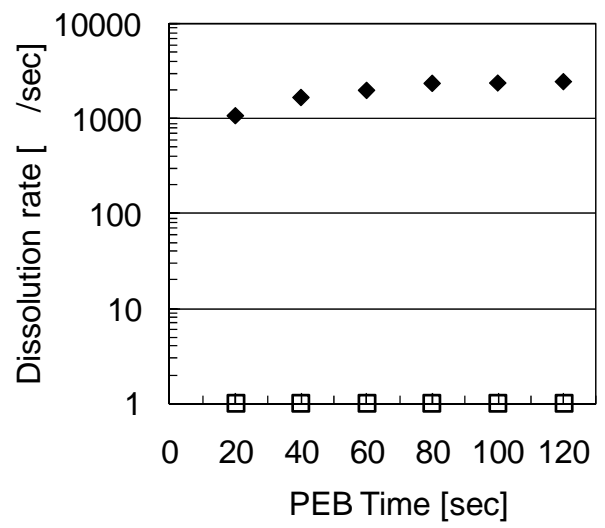

Figure 5. Effect of PEB time on the dissolution rate for PIPHI/TBMPF/PTMA (80/16/4 wt/wt/wt) resist system in exposed $(\diamond)$ and unexposed $(\square)$ areas. The prebake, $g$-line exposure, and PEB temperature were fixed at $100{ }^{\circ} \mathrm{C}$ for $2 \mathrm{~min}$, at $200 \mathrm{~mJ} / \mathrm{cm}^{2}$ and at $100{ }^{\circ} \mathrm{C}$, respectively.

Based on these preliminary optimization studies involving TBMPF loadings, PEB temperature and PEB time, a PSPHI consisting of the PIPHI (80 wt\%), TBMPF (16 wt\%), and PTMA (4 wt\%) was formulated. The photosensitivity curve of resist film with a 1.7 $\mu \mathrm{m}$ thickness is shown in Figure 6, and the outstanding sensitivity $\left(\mathrm{D}_{0.5}\right)$ and contrast with $g$-line are $25 \mathrm{~mJ} / \mathrm{cm}^{2}$ and 8.4 , respectively. This PSPHI using TBMPF as the DI shows high sensitivity and good contrast due to the chemically amplified system.

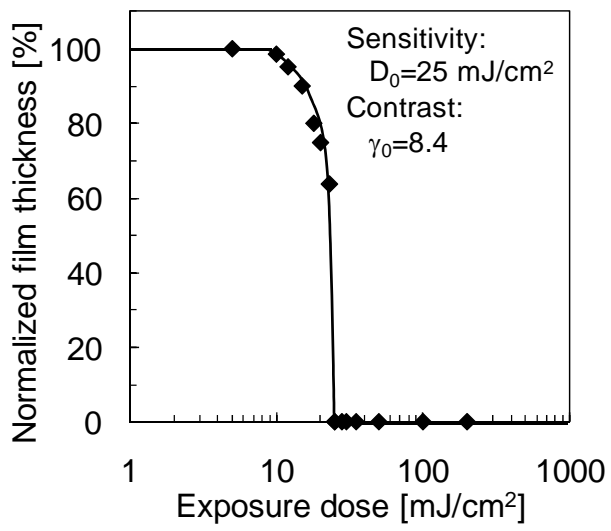

Figure 6. Characteristic photosensitive curve for PIPHI/TBMPF/PTMA (80/16/4 wt/wt/wt) resist system with a $1.7 \mu \mathrm{m}$ film thickness. The prebake and PEB conditions were fixed as $100{ }^{\circ} \mathrm{C}$ for $2 \mathrm{~min}$ and at $130{ }^{\circ} \mathrm{C}$ for $2 \mathrm{~min}$, respectively.
The positive-tone image of the PSPHI using a $2.2 \mu \mathrm{m}$ thick film was fabricated under the exposure to $50 \mathrm{~mJ} / \mathrm{cm}^{2}$ with $\mathrm{g}$-line, post-baked at $130{ }^{\circ} \mathrm{C}$ for $2 \mathrm{~min}$, and developed with 2.38wt\% TMAHaq. $/ 10 \mathrm{wt} \% \mathrm{PrOH}$ at $25{ }^{\circ} \mathrm{C}$. (Figure 7) A clear, positive pattern with a $4 \mu \mathrm{m}$ feature could be obtained.

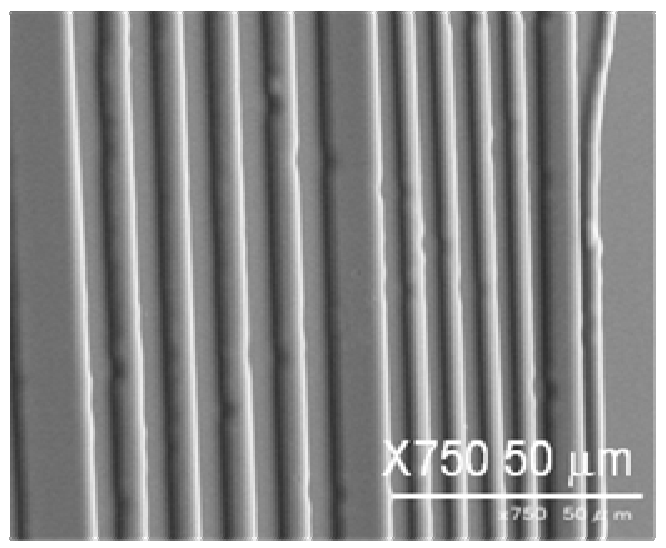

Figure 7. SEM image of positive-pattern of PSPHI film (thickness: $2.2 \mu \mathrm{m}$ ).

\subsection{Optical Property of PSPHI Film.}

Table 1 summarizes optical properties of the pristine PHI and the PSPHI films, including transmittances at $450 \mathrm{~nm}\left(T_{450}\right)$, film thicknesses, $n_{\mathrm{TE}}, n_{\mathrm{TM}}, n_{\mathrm{av}}$ measured at $633 \mathrm{~nm}$ wavelength, and $\Delta n$. The $n_{\mathrm{av}}$ and $\Delta n$ of the pristine PHI film are 1.7081 and 0.0045 , respectively. On the other hand, those of the PSPHI film slightly decrease due to the residues of TBMPF and PTMA. The PSPHI film shows high transparency at $450 \mathrm{~nm}$ in spite of presence of photosensitizing agents in the PSPHI film. The chemically amplified system and the usage of a small amount of PTMA provide high transparency.

Table 1. Optical Properties of PHI and PSPHI Films.

\begin{tabular}{cccccc}
\hline Film & $\begin{array}{c}T_{450} \\
{[\%]}\end{array}$ & $n_{\mathrm{TE}}$ & $n_{\mathrm{TM}}$ & $n_{\mathrm{AV}}$ & $\Delta n^{\mathrm{b}}$ \\
\hline $\mathrm{PHI}$ & 87 & 1.7096 & 1.7051 & 1.7081 & 0.0045 \\
$\mathrm{PSPHI}$ & 67 & 1.6989 & 1.6964 & 1.6980 & 0.0025 \\
\hline${ }^{\mathrm{a}}$ Conditions for the preparation of $\mathrm{PSPHI}$ film: The \\
resist film (PIPHI/TBMPF/PTMA (80/16/4 wt/wt/wt)) \\
was cured at 200 ${ }^{\circ} \mathrm{C}$ for $30 \mathrm{~min}$. \\
${ }^{\mathrm{b}}$ Birefringence: $\Delta n=n_{\mathrm{TE}}-n_{\mathrm{TM}}$.
\end{tabular}

\section{Conclusions}

A novel high- $n$ and positive-type PSPHI using the PIPHI as a matrix polymer has been developed. This PSPHI consisting of the PIPHI, TBMPF, and PTMA showed a excellent 
sensitivity $\left(25 \mathrm{~mJ} / \mathrm{cm}^{2}\right)$ and contrast (8.4) with $g$-line exposure, and the clear positive image of PSPHI was obtained. Moreover, the PSPHI film had high refractive index and good transparency at $450 \mathrm{~nm}$.

\section{References}

1. (a) J. G. Liu and M. Ueda, J. Mater. Chem., 19 (2009) 8907. (b) J. G. Liu, Y. Nakamura, Y. Shibasaki, S. Ando and M. Ueda, Macromolecules, 40 (2007) 4614. (c) C. M. Chang, C. L. Chang and C. C. Chang, Macromol. Mater. Eng., 291 (2006) 1521. (d) C. L. Lu, Z. C. Cui, Y. X. Wang, B. Yang and J. C. Shen, J. Appl. Polym. Sci., 89 (2003) 2426. (e) C. A. Terraza, J. G. Liu, Y. Nakamura, Y. Shibasaki, S. Ando and M. Ueda, J. Polym. Sci., Part A: Polym. Chem., 46 (2008) 1510. (f) N-H. You, Y. Suzuki, D. Yorifuji, S. Ando and M. Ueda, Macromolecules, 41 (2008) 6361. (g) N-H. You, N. Fukuzaki, Y. Suzuki, Y. Nakamura, T. Higashihara, S. Ando and M. Ueda, J. Polym. Sci., Part A: Polym Chem., 47 (2009) 4428. (h) N-H. You, Y. Nakamura, Y. Suzuki, T. Higashihara, S. Ando and Ueda, J. Polym.
Sci., Part A: Polym. Chem., 47 (2009) 4886. (i) N. Fukuzaki, T. Higashihara, S. Ando and M. Ueda, Macromolecules, 43 (2010) 1836 (j) N-H. You, T. Higashihara, S. Ando and M. Ueda, J. Polym. Sci., Part A: Polym. Chem., 48 (2010) 656.

2. (a) J. G. Liu, Y. Nakamura, T. Ogura, Y. Shibasaki, S. Ando and M. Ueda, Chem. Mater, 20 (2008) 273. (b) Y. Saito, T. Higashihara and M. Ueda, J. Photopolym. Sci. Technol., 22 (2009) 423.

3. (a) X. Z. Jin and H. Ishii, J. Appl. Polym. Sci., 98 (2005) 15. (b) T. Omote, K. Koseki and T. Yamaoka, Macromolecules, 23 (1990) 4788.

4. T. Ogura, T. Higashihara and M. Ueda, $J$. Photopolym. Sci. Technol., 22 (2009) 429.

5. J. G. Liu, Y. Nakamura, Y. Shibasaki, S. Ando and M. Ueda, J. Polym. Sci., Part A: Polym. Chem., 45 (2007) 5606.

6. Y. Saito, K. Mizoguchi, T. Higashihara and M. Ueda, J. Appl. Polym. Sci., 113 (2009) 3605.

7. G. Maier, Prog. Polym. Sci., 26 (2001) 3.

8. Y. Shibasaki, F. Toyokawa, S. Ando and M. Ueda, Polymer J., 39 (2006) 81. 